\title{
Expression of orphan GPR56 correlates with tumor progression in human epithelial ovarian cancer
}



${ }^{1}$ The Maternal Health Care and Birth Control Center of Yinan County, Linyi, Shandong, China; ${ }^{2}$ Department of Neurosurgery, Yidu Central Hospital of Weifang, Weifang, Shandong, China; ${ }^{3}$ Second Department of Paediatrics, Shouguang People's Hospital, Shouguang, Shandong, China; ${ }^{4}$ Linyi People's Hospital, Linyi, Shandong, China; ${ }^{5}$ General Department, Shandong Provincial Hospital Affiliated to Shandong University, Jinan, Shandong, China; ${ }^{6}$ Department of Medical Oncology, The Affiliated Yantai Yuhuangding Hospital of Qingdao University, Yantai, Shandong Province, China

*Correspondence: hubaohong81@163.com, lipengsdyt@163.com

Received March 29, 2016 / Accepted July 29, 2016

\begin{abstract}
G protein-coupled receptor 56 (GPR56) has been demonstrated to be a significant prognostic predictor in several types of malignances, including melanoma, glioblastoma, breast cancer, colon cancer, and pancreatic cancer. GPR56 has a putative mucin-like extracellular domain, indicating functions for this receptor in the cell-cell interactions and triggering different downstream signaling pathways responsible for regulating cell survival, proliferation, adhesion, and migration. But the expression and clinical significance of GPR56 has not been elucidated in epithelial ovarian cancer (EOC). We detected GPR56 expression by immunohistochemistry in 110 samples of ovarian serous carcinoma to explore the correlation between its expression and clinicopathologic characteristics and overall survival. As the result, we found that GPR56 expression is significantly associated with advanced FIGO stage $(\mathrm{P}=0.01)$ and positive lymph node invasion $(\mathrm{P}=0.016)$, and it serves as an independent unfavorable prognostic factor through univariate and multivariate analysis. GPR56 knockdown could dramatically decrease the proliferation and invasion of epithelial ovarian cancer cells through down-regulating the RhoA-GTP level and up-regulating the E-cadherin level, which indicates GPR56 could promote the progression and invasion of EOC. In conclusion, GPR56 expression was demonstrated as an independent prognostic factor in EOC, suggesting that GPR56 may play an oncogenic role through the Rho and E-cadherin pathway and GPR56 could be a novel potential drug target in EOC.
\end{abstract}

Key words: epithelial ovarian cancer, G protein-coupled receptor 56, invasion, prognosis

Ovarian cancer is the one of the most lethal malignancies [1], constituting approximately $90 \%$ of ovarian tumors. There are about 200,000 newly diagnosed patients yearly worldwide [2]. Prognosis of ovarian cancer is now improved by advanced surgical procedures and better medical management, but the long-term survival remains unsatisfied; The 5-year overall survival (OS) of epithelial ovarian cancer (EOC) was only about $30-50 \%$ for patients with advanced-stage disease [3]. Moreover, EOC is difficulty to be diagnosed at an early stage due to the lack of early symptoms as well as limited specificity and sensitivity of diagnostic markers [4-6]. Therefore, finding out novel biomarkers for better EOC diagnosis, elucidating its biologic behavior and identifying potential therapeutic targets are still under critical demands.
G protein-coupled receptor (GPCR) constitute one of the largest families of membrane proteins, investigation and understanding their activation mechanism are important for development of new drugs since at least $30 \%$ of drugs target GPCRs nowadays [7, 8]. GPR56 belongs to the adhesion GPCRs, characterized with a long extracellular domain (ECD) and transmembrane domain (TM). It has been reported that CD81 [9], collagen III [10] and transglutaminase 2 (TG2) [11], are all interactors of GPR56.

Previously research indicated GPR56 activates the Rho pathway and functions in the neural progenitor cell migration [12]. Recently, some reports demonstrated that GPR56 contributes to tumorigenesis, including melanoma [13], breast cancer, colon cancer [14] and glioblastoma [15]. It was 
involved in regulating cell survival, proliferation, adhesion, and migration $[12,16]$. However, the function of GPR56 in ovarian cancer hasn't been studied. Here we analyzed the expression and signaling transduction of GPR56 in human EOC.

\section{Patients and methods}

Samples and patients. Paraffin-embedded ovarian serous carcinoma tissues were obtained from 110 patients at Linyi People's Hospital, Shandong, China. All the patients were diagnosed with serous ovarian cancer without any preoperative chemotherapy or radiotherapy, diagnosis was confirmed by pathological examination after surgical section. All patients were under careful nursing: without food or drink before operation, closely electrocardiogram monitoring, proper diet control after operation and enough period of hospital stays, etc. Follow-up time was defined as the period since the surgery to the date of death or to the last clinical follow-up time (December 2014). Another 18 samples of fresh-resected ovarian serous carcinoma tissues and paired adjacent ovarian tissues were collected from EOC patients. We also collected 15 samples of normal ovarian tissues from nontumorous patients (biopsy of ovarian or adnexectomy due to adenomyosis). The sample possession was permitted by the Medical Ethics Committee in our hospital. Written informed consents were acquired from all patients.

Immunohistochemistry (IHC). For IHC, formalin-fixed paraffin-embedded sample sections were dewaxed in xylene and then rehydrated, and subsequently performed antigen retrieval with citrate buffer $\mathrm{pH}$ 6.0. The slides were then incubated with the GPR56 antibody (1:100, HPA046065, Sigma) at $4^{\circ} \mathrm{C}$ overnight after blocked, detected the immunoreactivity using the DAB staining kit (Tiangen, China) and haematoxylin counterstaining. $5 \%$ fetal bovine serum (FBS) was used as negative control.

Assessment of immunohistochemical staining. This study follows the criterions of double-blind trials. We asked two independent pathologists to perform the immunoreactivity scoring for GPR56 expression. Both the staining intensity (score 0, negative staining; score 1, pale yellow; score 2, dark yellow; score 3, brown) and the percentage of positive cells were scored (score $0,<10 \%$ positive cells; score $1,10 \%-25 \%$ positive cells; score 2, 25\%-50\% positive cells; score 3, 50\%$75 \%$ positive cells; and score $4,>75 \%$ positive cells). The final staining result was evaluated by the product of the two scores (range: 0-12), and the GPR56 staining results were classified into low expression $(<6)$ and high expression $(\geq 6)$.

Cell culture and siRNA transfection. The human ovarian cancer lines SKOV3 were cultured in RPMI 1640 medium with $10 \% \mathrm{FBS}, 100 \mu \mathrm{g} / \mathrm{mL}$ streptomycin and $100 \mathrm{U} / \mathrm{mL}$ penicillin. The targeting sequence for GPR56-specific siRNA nucleotides was 5'-AGAUUACAUCUUCUCUAUGGCAAGC-3' and the control siRNA sequence was 5'-UUCUCCGAACGUGUCACGU-3'. Both siRNA duplexes were designed and synthesized by GenePharma (Shanghai, China). The siRNA transfection was performed using the Lipofectamine trans- fection reagent (Invitrogen) according to manufacturer's instructions.

Western blot analysis. The tissues and cells were lysed in RIPA lysis buffer (Beyotime Biotechnology, Shanghai, China) according to the instructions. The overall protein concentration was determined using BCA Protein assay kit (Thermo Fisher Pierce, USA). Approximately $20 \mu \mathrm{g}$ of the denatured samples was separated with SDS-PAGE and transferred to the PVDF membrane (Bio-Rad, USA). The membrane was incubated overnight with primary antibodies for GPR56 (ab172361, Abcam, USA), RhoA (ab187027, Abcam, USA), RhoA-GTP (\#26904, NewEast Biosciences, USA), E-cadherin (sc-7870, Santa Cruz, USA) and actin (sc-1616, Santa Cruz, USA) at $4^{\circ} \mathrm{C}$. Then incubate the membrane with relative horseradish peroxidase-conjugated secondary antibodies for $1 \mathrm{~h}$ at $37^{\circ} \mathrm{C}$, finally visualize the protein expression by ECL reagent (Thermo Fisher Pierce, USA).

MTT assay and cell migration assay. MTT assay was performed on SKOV3 cells, with control group or after siRNA of GPR56. Cells were seeded into 96-well plates at the density of $2 \times 10^{3}$ cells/well with six replicates each group. $0.5 \%$ MTT were added at $0,24,48,72,96$ and 120 hours after cell seeding. Removed the medium after culturing for another 4 hours, and then added $150 \mu \mathrm{L}$ DMSO to each well. The absorbance was read at the wavelength of $570 \mathrm{~nm}$ on the microplate reader (Bio-Rad, USA) after cells were incubated for 15 minutes. Each experiment was repeated at least three times and normalized with the total cell numbers.

For the cell migration assay, SKOV3 cells were seeded into the upper chamber of transwells (Millipore, USA) at the density of $2 \times 10^{5}$ cells/well. After culturing 6 hours for cell adhesion, starved the cells for another 24 hours using RPM1 1640 medium with $1 \%$ FBS. RPMI 1640 containing 10\% FBS was added into the lower chamber at the same time. After starvation, gently removed the non-migratory cells by scraping with cotton swab. And the cells migrated to the lower surface were stained with $0.1 \%$ crystal violet. Account the cells in six random fields and determine the total number of invading cells. All assays were repeated at least three times.

Statistical analysis. Statistical analysis was performed using SPSS19.0 software (SPSS, Chicago, IL, USA). The association between GPR56 expression and clinicopathological variables of patients was assessed using Chi-square test. Overall KaplanMeier survival analysis was performed and compared using log-rank test. The multivariate logistic regression analysis was also used to identify the independent prognostic factors. In this study, some clinicopathologic parameters were combined and compared as follows: Age: $\leq 60$ vs. $>60$ years; FIGO stage: I-II vs. III-IV; CA-125: $\leq 900$ vs. $>900 \mathrm{U} / \mathrm{mL}$. P values less than 0.05 were considered as statistically significant.

\section{Results}

Characteristics of EOC patients. 110 cases diagnosed with ovarian serous carcinoma were included in this study after 

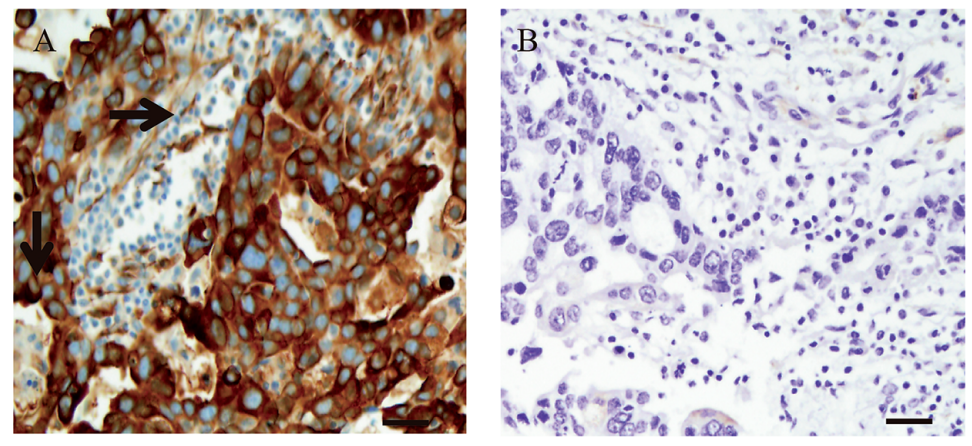



$\mathrm{E}$
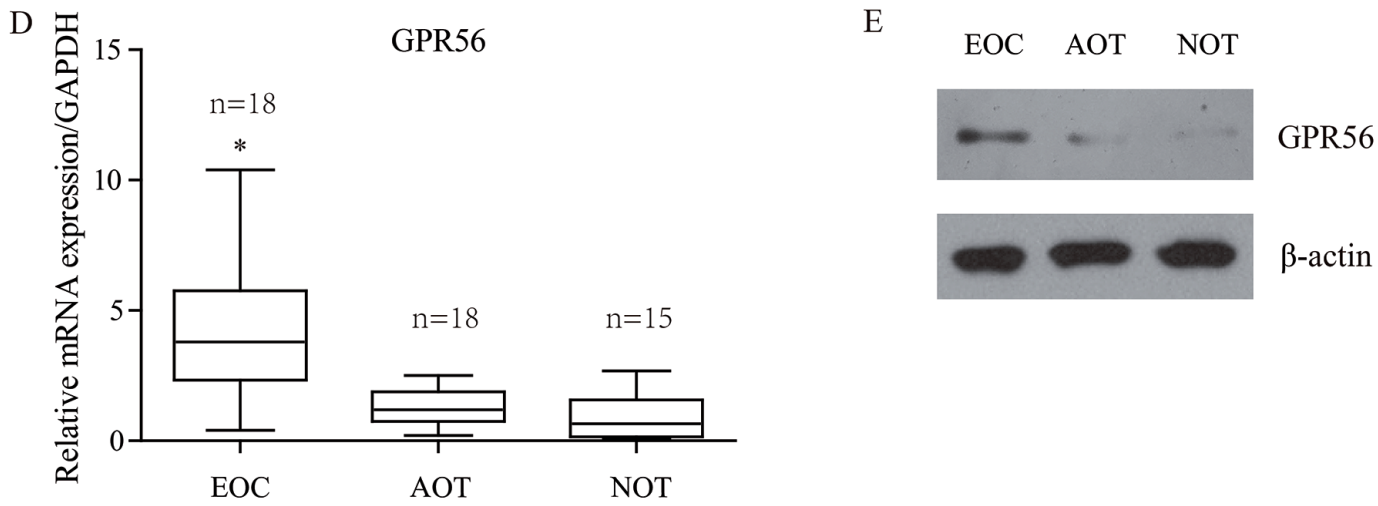

Figure 1. GPR56 expression in EOC. (A) Representative higher GPR56 staining in EOC cancer tissues. In this field, the score of positive cell percentage is 4 and the score of staining intensity is 3 . So the total score is 12 (calculated by score of positive cell percentage multiplying score of staining intensity) and defined as GPR56 high-expression. Arrows pointed the strong IHC staining. (B) Representative lower GPR56 staining in adjacent ovarian tissues (AOT); The score of positive cell percentage is 1 and the score of staining intensity is 0 . Total score is 0 thus defined as GPR56 low-expression. (C) IHC result of GPR56 expression in normal ovarian tissues (NOT) from nontumorous patients; Both the score of positive cell percentage and staining intensity is 0, which was defined as GPR56 low-expression. (D) RT-qPCR results revealed the mRNA level of GPR56 from fresh frozen EOC, AOT and NOT

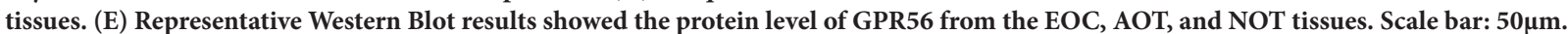

Table 1. Basic clinicopathologic characteristics of patients and the correlation with GPR56 expression

\begin{tabular}{lcccc}
\hline Variables & Cases & \multicolumn{2}{c}{ GPR56 expression } & \multirow{2}{*}{ P value } \\
\cline { 2 - 4 } & $(\mathbf{n = 1 1 0})$ & Low (n, \%) & High (n, \%) & \\
\hline Age (years) & 73 & $47(64.4 \%)$ & $26(35.6 \%)$ & 0.530 \\
$\quad \leq 60$ & 37 & $20(54.1 \%)$ & $17(45.9 \%)$ & \\
$\quad>60$ & & & & 0 \\
$\quad$ Pathological grade & 30 & $22(73.3 \%)$ & $8(26.7 \%)$ & \\
$\quad$ G1 & 38 & $21(55.3 \%)$ & $17(44.7 \%)$ & \\
$\quad$ G2 & 42 & $24(57.1 \%)$ & $18(42.9 \%)$ & \\
$\quad$ G3 & & & & $0.001^{*}$ \\
FIGO stage & 50 & $38(76.0 \%)$ & $12(24.0 \%)$ & \\
$\quad$ I II & 60 & $28(46.7 \%)$ & $32(53.3 \%)$ & \\
$\quad$ III IV & & & & 0.219 \\
Pre-operative CA-125 & 49 & $33(67.3 \%)$ & $16(32.7 \%)$ & \\
$\quad \leq 900$ & 61 & $34(55.7 \%)$ & $27(44.3 \%)$ & \\
$\quad>900$ & & & & $0.016^{*}$ \\
LN metastasis & 69 & $48(69.6 \%)$ & $21(30.4 \%)$ & \\
$\quad$ Negative & 41 & $19(46.3 \%)$ & $22(53.7 \%)$ & \\
$\quad$ Positive & & & & \\
\hline
\end{tabular}

Note: ${ }^{*}$ Statistically significant;

Abbreviations: FIGO, International Federation of Gynecology and Obstetrics; GPR56, G protein-coupled receptor 56; LN, lymph node. exclusion of certain cases such as patients accepted the preoperative chemotherapy or pathologically non-serous carcinoma, etc. The patients were aged from 41 to 72 years (median 53.0 years); As for the histopathologic grading, 30 patients (27.3\%) were diagnosed with G1, 38 patients (34.5\%) with G2 and other 42 patients $(38.2 \%)$ with G3, respectively. TNM staging was determined using the International Federation of Gynecology and Obstetrics (FIGO) staging system. According to the FIGO stage, 17 cases $(15.5 \%)$ had stage I, 33 cases $(30.0 \%)$ had stage II, 42 cases (38.2\%) had stage III, and 18 cases $(16.4 \%)$ had stage IV. Among the 110 patients, 41 patients $(37.3 \%)$ had positive lymph node (LN) metastasis, while no metastasis was found in the other 69 patients (62.7\%). The 5-year OS of the enrolled patients was $67.8 \%$. Table 1 summarizes the clinicopathological characteristics of the patients.

GPR56 is overexpressed in EOC tissues. We performed IHC analysis of the cancer tissues as well as corresponding adjacent tissues with GPR56 antibody. As shown in Figure 1, GPR56 exhibited cytoplasm and membrane staining in cancer cells.

As described in Patients and Methods, we used the total score calculated by staining intensity score multiplying the 
score of positive cell percentage to identify the expression of GPR56, which ranged from 0 to 12 . The cut-off of the score was set as 6, dividing this validation cohort into GPR56 high-expression group and low-expression group. Of all cancer tissues, $39.1 \%$ (43/110) showed high GPR56 expression, whereas all the adjacent ovarian tissues from ovarian cancer patients (AOT) and normal ovarian tissues from nontumorous patients (NOT) showed negative GPR56 staining (Figure 1A-1C). In addition, we performed the RT-qPCR analysis to evaluate the mRNA level of GPR56 in NOT, AOT, and EOC tissues. The RT-qPCR results showed that mRNA level of GPR56 in EOC was 4.21 fold higher than that in NOT, while no significant difference was detected between NOT and AOT (Figure 1D). We also carried out the Western Blot using the tissues above to better evaluate the protein expression of GPR56, and the results showed GPR56 protein level was much higher in EOC tissues than that in NOT and AOT (Figure 1E).

Taken together, these results indicated that GPR56 expression was up-regulated in human EOC tissues.

Relationship between GPR56 expression and clinicopathologic features in EOC patients. The correlation between GPR56 expression and clinicopathologic features of EOC patients was shown in Table 1. It was found that the level of GPR56 expression was significantly higher in patients with advanced FIGO stage $(\mathrm{P}=0.001)$ and with positive LN metastasis $(\mathrm{P}=0.016)$; whereas there was no correlation with age, pathological grade or pre-operative CA-125 level ( $\mathrm{P}=$ $0.530, \mathrm{P}=0.900$ and $\mathrm{P}=0.219$, respectively). These results indicated that GPR56 may participate in the progression and metastasis of EOC.

Univariate analysis and multivariate analysis of EOC patients. To evaluate the prognostic value of GPR56 in EOC, we further performed the univariate analysis with Kaplan-Meier method and multivariate analysis with Cox-regression model. As shown in Table 2, univariate analysis results indicated significant relationships between OS and clinicopathologic factors including age $(\mathrm{P}=0.011)$, pathological grade $(\mathrm{P}=$ $0.048)$, FIGO stage $(\mathrm{P}=0.001)$, LN metastasis $(\mathrm{P}=0.022)$ as well as GPR56 expression $(\mathrm{P}=0.002)$. GPR56 high expression was proved to be associated with poorer prognosis of EOC (Figure 2). By contrast, no significant correlation was detected between OS and pre-operative CA-125 level $(\mathrm{P}>0.05)$. Furthermore, the FIGO stage (hazard ratio [HR] $=3.65$, confidence interval $[\mathrm{CI}]=1.05 \sim 12.62 ; \mathrm{P}=0.041)$ and GPR56 expression $(\mathrm{HR}=2.31,[\mathrm{CI}]=1.02 \sim 5.22 ; \mathrm{P}=0.044)$ were identified as independent prognostic factors of EOC patients, as revealed by the multivariate survival analysis.

GPR56 promotes proliferation and invasion of epithelial ovarian cancer cells. We delete the expression of GPR56 through siRNA to evaluate the function of GPR56 in ovarian cancer cell line SKOV3 (Figure 3A). Interestingly, we found that knock-down of GPR56 can down-regulate the expression level of RhoA-GTP while the expression of E-cadherin was up-regulated. MTT assay was performed to determine the effects of GPR56 on cell proliferation. As shown in
Table 2. Kaplan-Meier survival analysis (log-rank test) of patients with epithelial ovarian cancer

\begin{tabular}{|c|c|c|c|c|}
\hline \multirow[t]{2}{*}{ Variables } & \multirow{2}{*}{$\begin{array}{c}\text { Cases } \\
(n=110)\end{array}$} & \multicolumn{2}{|c|}{$\begin{array}{l}\text { Overall survival time } \\
\text { (months) }\end{array}$} & \multirow[t]{2}{*}{$P$ value } \\
\hline & & Mean, sd & $\begin{array}{c}\text { 5-year } \\
\text { survival rate }\end{array}$ & \\
\hline Age (years) & & & & $0.011^{*}$ \\
\hline$\leq 60$ & 73 & $74.9 \pm 3.7$ & $75.6 \%$ & \\
\hline$>60$ & 37 & $55.6 \pm 3.8$ & $57.8 \%$ & \\
\hline Pathological grade & & & & $0.048^{*}$ \\
\hline G1 & 30 & $80.2 \pm 5.8$ & $69.1 \%$ & \\
\hline G2 & 38 & $67.4 \pm 3.5$ & $78.0 \%$ & \\
\hline G3 & 42 & $57.0 \pm 3.5$ & $50.4 \%$ & \\
\hline FIGO stage & & & & $0.001^{\star}$ \\
\hline $\mathrm{I} / \mathrm{II}$ & 50 & $77.7 \pm 3.6$ & $81.4 \%$ & \\
\hline III/IV & 60 & $54.8 \pm 2.6$ & $54.9 \%$ & \\
\hline Pre-operative CA-125 & & & & 0.251 \\
\hline$\leq 900$ & 49 & $71.8 \pm 3.5$ & $70.9 \%$ & \\
\hline$>900$ & 61 & $65.9 \pm 4.2$ & $67.4 \%$ & \\
\hline LN metastasis & & & & $0.022^{\star}$ \\
\hline Negative & 69 & $74.0 \pm 3.6$ & $74.0 \%$ & \\
\hline Positive & 41 & $55.0 \pm 3.2$ & $57.1 \%$ & \\
\hline GPR56 expression & & & & $0.002^{*}$ \\
\hline Low expression & 67 & $78.8 \pm 3.7$ & $74.3 \%$ & \\
\hline High expression & 43 & $57.0 \pm 4.0$ & $61.9 \%$ & \\
\hline
\end{tabular}

Note: ${ }^{*}$ Statistically significant;

Abbreviations: FIGO, International Federation of Gynecology and Obstetrics; LN, lymph node; GPR56, G protein-coupled receptor 56; LN, lymph node.

Figure 3B, GPR56-siRNA had an inhibitory effect on cell proliferation. The proliferation of the GPR56-siRNA group was decreased by $42 \%$ and $53 \%$ on the $4^{\text {th }}$ day and $5^{\text {th }}$ day after knock-down compared with that of the control-siRNA group, respectively.

The effect of GPR56 on cell migration was assessed by the transwell migration assay (Figure 3C). The migration ability of GPR56-siRNA SKOV3 cells was significantly reduced $(\mathrm{P}<0.01)$ compared with that of control group by about $40 \%$. Thus, GPR56 was extremely effective in increasing the invasive capability of SKOV3 cells.

Table 3. Multivariate analysis of the clinicopathological parameters with OS in EOC patients

\begin{tabular}{lccc}
\hline Variables & Hazard ratio & 95\% Confidence Interval & P value \\
\hline Age & 4.21 & $0.50 \sim 35.65$ & 0.187 \\
FIGO stage & 3.65 & $1.05 \sim 12.62$ & $0.041^{*}$ \\
Pathological grade & 0.75 & $0.23 \sim 2.40$ & 0.622 \\
LN metastasis & 0.81 & $0.27 \sim 2.44$ & 0.703 \\
GPR56 expression & 2.31 & $1.02 \sim 5.22$ & $0.044^{*}$ \\
\hline
\end{tabular}

Note: ${ }^{*}$ Statistically significant;

Abbreviations: FIGO, International Federation of Gynecology and Obstetrics; LN, lymph node; GPR56, G protein-coupled receptor 56. 


\section{Discussion}

EOC is the leading lethal cause among gynecologic malignancies. Despite the recent advances, over $60 \%$ of EOC cases are diagnosed at the advanced stage due to the asymptomatic nature in its early stage of this disease. EOC accounts for $90 \%$ of all ovarian cancers and the epithelial serous ovarian cancer

A

OS Curve According to Age

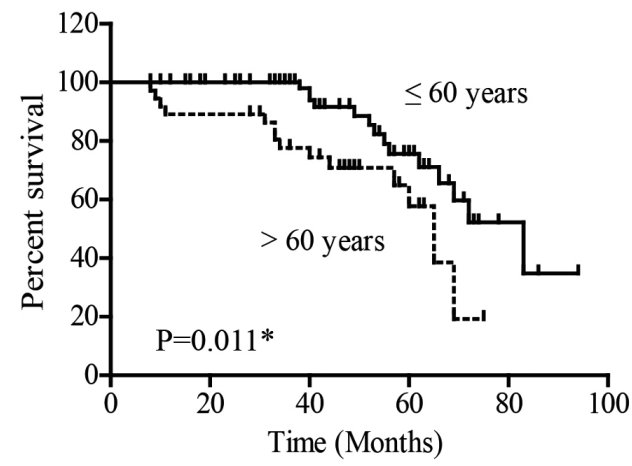

C

OS Curve According to FIGO Stage

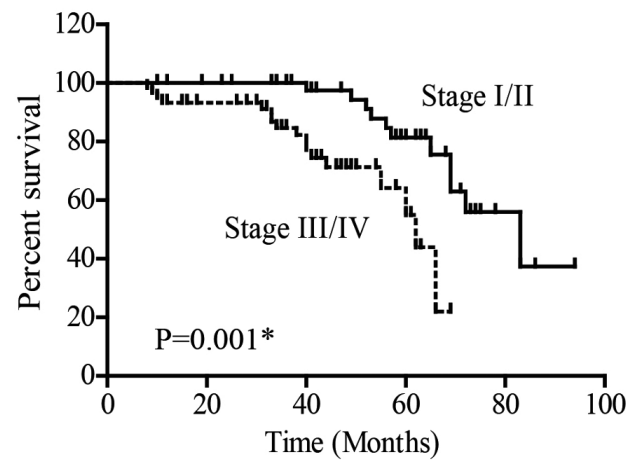

E
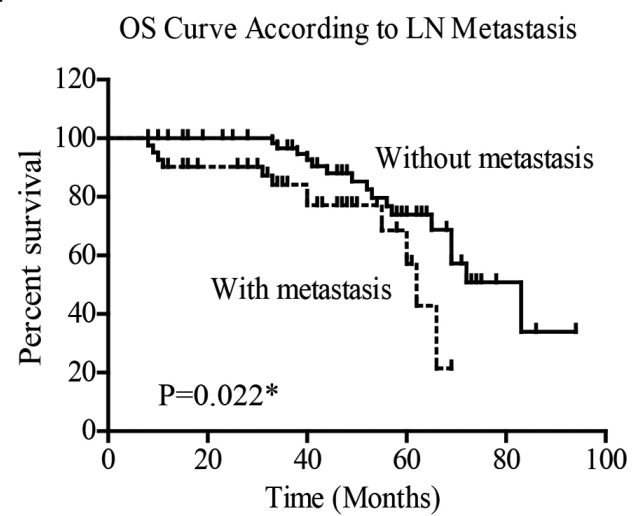

has the highest incidence. Over the last several decades, CA125 has been used for distinguishing the malignant cancer from benign pelvic masses, monitoring response to treatment and recurrence of EOC [17-19]. However, the sensitivity and specify of serum CA-125 is not satisfied for EOC screening and prognostic evaluate [20]. There were reports revealing that serum CA-125 levels may be even in the normal range in about

B

OS Curve According to Pathological Grade

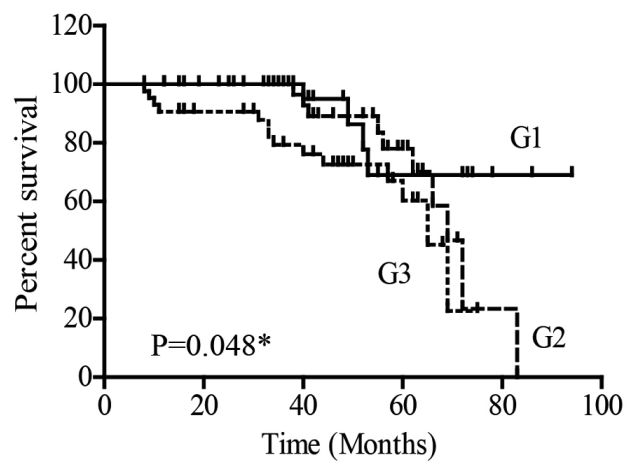

$\mathrm{D}$

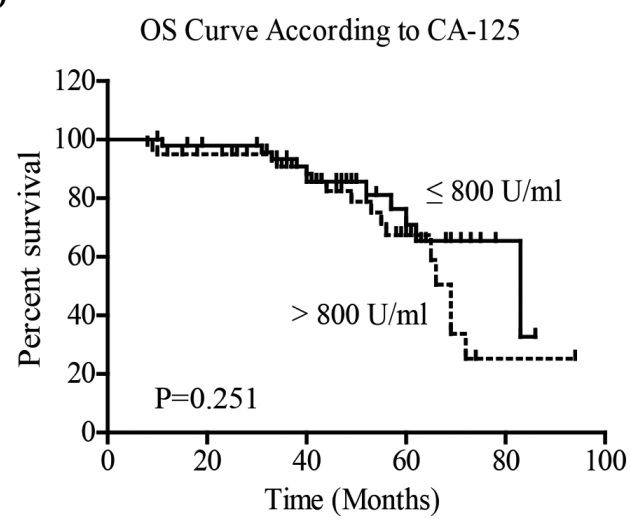

F

OS Curve According to GPR56 Expression

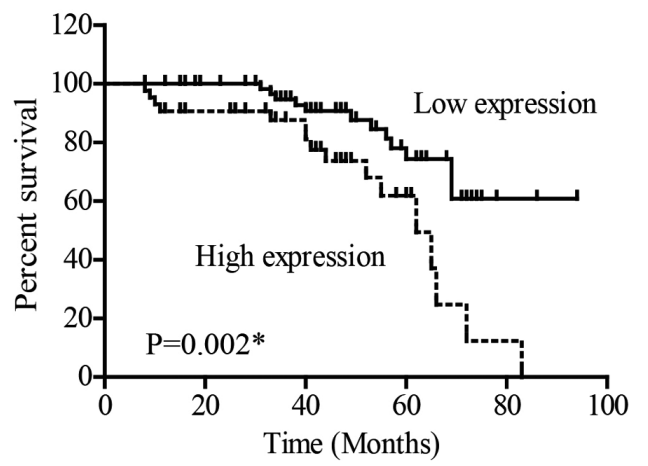

Figure 2. Kaplan-Meier analysis of OS.

Patients with older age (A), advanced pathological grade (B), later FIGO stage (C), LN metastasis (E) and higher GPR56 protein expression level (F) had unfavorable OS (log-rank test, $\mathrm{P}<\mathbf{0 . 0 5}$ ). While there was no significant difference of OS between patients with higher or lower pre-operative $\mathrm{CA}$ 125 level. (log-rank test, $\mathrm{P}=\mathbf{0 . 2 5 1}$ ). 
A
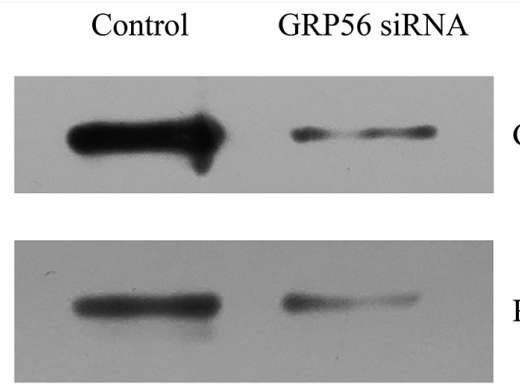

RhoA-GTP
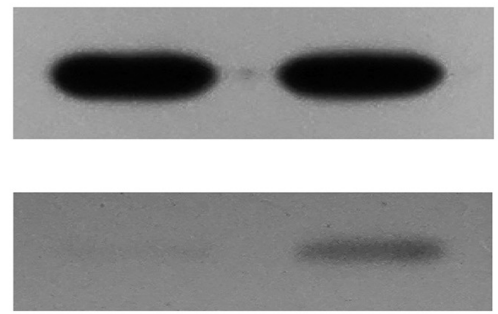

E-cadherin

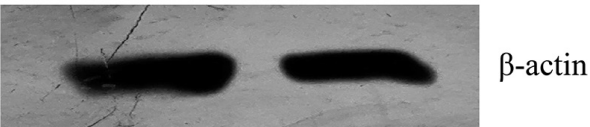

Total RhoA
B

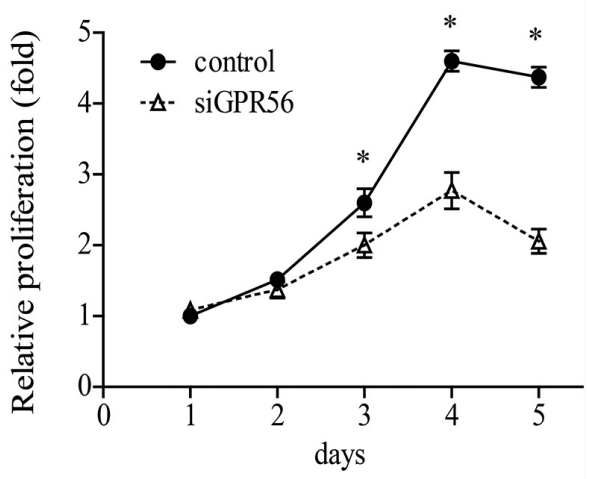

$\mathrm{C}$

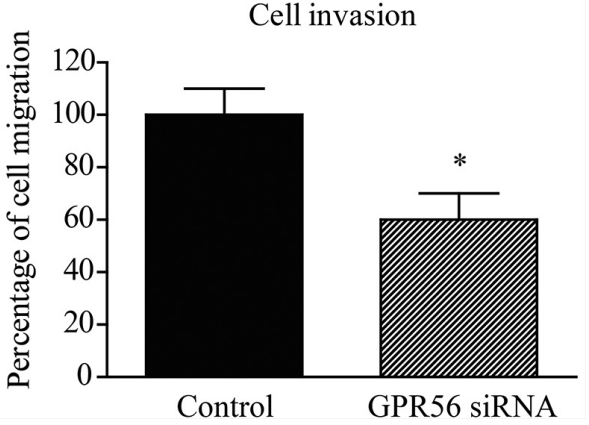

Figure 3. Knock-down of GPR56 could attenuate the proliferation and invasion ability of SKOV3 cells.

(A) GRP56-siRNA could successfully knock down the expression of GPR56 protein (upper panel), and consequently reduced the expression level of RhoA-GTP (second panel) without changing the total RhoA level (third panel), while increase the expression of E-cadherin (fourth panel) in SKOV3 cells. (B) GPR56-siRNA could down-regulate the proliferation (B) and invasion (C) capacity of SKOV3 cells demonstrated by MTT assay and migration assay, respectively. (Data are presented as the averages of triplicate experiments. $\mathrm{P}<0.05$ )

$50 \%$ of stage I patients and in more than $10 \%$ of advanced-stage patients [21-23]. The detection of more valuable diagnostic and prognostic biomarkers of EOC to improve its outcomes remains a challenge.

GPR56 is a member of adhesion GPCRs (or LN-TM7), belongs to class B/secretin-like GPCR subtype [24-26]. High mRNA levels of GPR56 have been reported in thyroid, heart and brain. The existence of the putative mucin-like extracellular domain of GPR56 has been suggested possible functions for this receptor in the cell-cell interactions. Recently emerging studies on GPR56 indicate that it may play an important role in human carcinomas. Overexpression of GPR56 has been reported in the human gliomas [15] and esophageal squamous cell carcinoma [27]. However, the expression of GPR56 protein was demonstrated to be down-regulated in metastatic melanoma and inhibits the tumor growth and metastasis [13]. It would be interesting to study whether GPR56 plays distinct roles in different cancers. To further confirm its functions, we investigated the expression and effects of GPR56 in human epithelial ovarian cancer.

In our study, we identified the expression of GPR56 protein in EOC and analyzed the correlation between GPR56 and OS for the first time. Our results revealed that GPR56 expression in EOC tissues was higher than that in adjacent tissues and normal ovarian tissues, indicating the important role of GPR56 in the tumorgenesis. To further validate our results, we searched the oncomine database (www.oncomine.org), which provides the gene expression information. There have been two studies from different groups demonstrated that the gene expression level of GPR56 in ovarian serous adenocarcinoma is 2.566 [28] and 2.635 [29] fold higher than that in normal ovarian tissues, respectively. Both the two studies consistent with our results. Moreover, GPR56 was identified as an independent prognostic predictor for EOC through univariate analysis and multivariate analysis. In addition, we demonstrated that GPR56 could promote the proliferation as well as invasion of epithelial ovarian cancer cell lines with experiments in vitro, indicating that GPR56 may play the oncogenic role in EOC. As for the signaling transductions, we found that the effects of GPR56 was at least partially mediated by the Rho and E-cadherin pathways. Thus, GPR56 could be considered as a potential drug target in the treatment of EOC. To our knowledge, this is the first report determining the overexpression of GPR56 in EOC. However, more experiments should be done to further demonstrate the regulatory mechanisms and functions of GPR56 in different cancers. 


\section{Conclusion}

In conclusion, we detected the expression of GPR56 in EOC and analyzed its correlation with clinicopatholgic features as well as overall survival rate. As a result, we found that GPR56 expression is significantly associated with advanced FIGO stage, positive lymph nodes metastasis and poorer prognosis. With cellular assays, we demonstrated that GPR56 knockdown could inhibit the proliferation and invasion capacity of epithelial ovarian cancer cells through Rho and E-cadherin pathways, suggesting the potential therapeutic role of GPR56 as a drug target.

Acknowledgments: This study was funded by Science and Technology Project of Yantai City (2015WS018), and Youth Research Initiation Fundation of Yuhuangding Hospital (201511). Science and Technology Project of Yantai City (2016WS006); Medicine and Health Science Development Project of Shandong (2016WS0706).

\section{References}

[1] JEMAL A, SIEGEL R, WARD E, MURRAY T, XU J et al. Cancer statistics, 2007. CA Cancer J Clin 2007; 57: 43-66. http://dx.doi.org/10.3322/canjclin.57.1.43

[2] FERLAY J, SHIN HR, BRAY F, FORMAN D, MATHERS C et al. Estimates of worldwide burden of cancer in 2008: GLOBOCAN 2008. Int J Cancer 2010; 127: 2893-2917. http://dx.doi. org/10.1002/ijc.25516

[3] COLOMBO PE, FABBRO M, THEILLET C, BIBEAU F, ROUANET $P$ et al. Sensitivity and resistance to treatment in the primary management of epithelial ovarian cancer. Crit Rev Oncol Hematol 2014; 89: 207-216. http://dx.doi.org/10.1016/j. critrevonc.2013.08.017

[4] JELOVAC D, ARMSTRONG DK. Recent progress in the diagnosis and treatment of ovarian cancer. CA Cancer J Clin 2011; 61: 183-203. http://dx.doi.org/10.3322/caac.20113

[5] SIEGEL R, NAISHADHAM D, JEMAL A. Cancer statistics for Hispanics/Latinos, 2012. CA Cancer J Clin 2012; 62: 283-298. http://dx.doi.org/10.3322/caac.21153

[6] GOFFBA, MANDELL, MUNTZHG, MELANCONCH. Ovarian carcinoma diagnosis. Cancer 2000; 89: 2068-2075. http:// dx.doi.org/10.1002/1097-0142(20001115)89:10<2068::AIDCNCR6>3.0.CO;2-Z

[7] LIU H-D, WANG W-B, XU Z-G, LIU C-H, HE D-F et al. FFA4 receptor (GPR120): A hot target for the development of antidiabetic therapies. European Journal of Pharmacology 2015; 763: 160-168. https://doi.org/10.1016/j.ejphar.2015.06.028

[8] LIU H, ZHANG Q, LI K, GONG Z, LIU Z et al. Prognostic significance of USP33 in advanced colorectal cancer patients: new insights into beta-arrestin-dependent ERK signaling. Oncotarget 2016 https://doi.org/10.18632/oncotarget.13219

[9] LITTLE KD, HEMLER ME, STIPP CS. Dynamic regulation of a GPCR-tetraspanin-G protein complex on intact cells: central role of CD81 in facilitating GPR56-Galpha q/11 association. Mol Biol Cell 2004; 15: 2375-2387. http://dx.doi.org/10.1091/ mbc.E03-12-0886
[10] CASEY BJ, SOMERVILLE LH, GOTLIB IH, AYDUK O, FRANKLIN NT et al. Behavioral and neural correlates of delay of gratification 40 years later: Proc. Natl. Acad. Sci. U.S.A. 2011, Vol 108 No. 36:14998-5003. Ann Neurosci 2012; 19: 27-28.

[11] XU L, HYNES RO. GPR56 and TG2: possible roles in suppression of tumor growth by the microenvironment. Cell Cycle 2007; 6: 160-165. http://dx.doi.org/10.4161/cc.6.2.3760

[12] IGUCHI T, SAKATA K, YOSHIZAKI K, TAGO K, MIZUNO $\mathrm{N}$ et al. Orphan G protein-coupled receptor GPR56 regulates neural progenitor cell migration via a $G$ alpha $12 / 13$ and Rho pathway. J Biol Chem 2008; 283: 14469-14478. http://dx.doi. org/10.1074/jbc.M708919200

[13] XU L, BEGUM S, HEARN JD, HYNES RO. GPR56, an atypical $G$ protein-coupled receptor, binds tissue transglutaminase, TG2, and inhibits melanoma tumor growth and metastasis. Proc Natl Acad Sci USA 2006; 103: 9023-9028. http://dx.doi. org/10.1073/pnas.0602681103

[14] KE N, SUNDARAM R, LIU G, CHIONIS J, FAN W et al. Orphan G protein-coupled receptor GPR56 plays a role in cell transformation and tumorigenesis involving the cell adhesion pathway. Mol Cancer Ther 2007; 6: 1840-1850. http://dx.doi. org/10.1158/1535-7163.MCT-07-0066

[15] SHASHIDHAR S, LORENTE G, NAGAVARAPU U, NELSON A, KUO J et al. GPR56 is a GPCR that is overexpressed in gliomas and functions in tumor cell adhesion. Oncogene 2005; 24: 1673-1682. http://dx.doi.org/10.1038/sj.onc.1208395

[16] LUO R, JEONG SJ, JIN Z, STROKES N, LI S et al. G proteincoupled receptor 56 and collagen III, a receptor-ligand pair, regulates cortical development and lamination. Proc Natl Acad Sci USA 2011; 108: 12925-12930. http://dx.doi.org/10.1073/ pnas. 1104821108

[17] DUFFY MJ, BONFRER JM, KULPA J, RUSTIN GJ, SOLETORMOS G et al. CA125 in ovarian cancer: European Group on Tumor Markers guidelines for clinical use. Int J Gynecol Cancer 2005; 15: 679-691. http://dx.doi.org/10.1111/j.15251438.2005.00130.x

[18] COHEN JG, WHITE M, CRUZ A, FARIAS-EISNER R. In 2014, can we do better than CA125 in the early detection of ovarian cancer? World J Biol Chem 2014; 5: 286-300. http:// dx.doi.org/10.4331/wjbc.v5.i3.286

[19] FELDER M, KAPUR A, GONZALEZ-BOSQUET J, HORIBATA S, HEINTZ J et al. MUC16 (CA125): tumor biomarker to cancer therapy, a work in progress. Mol Cancer 2014; 13: 129. http://dx.doi.org/10.1186/1476-4598-13-129

[20] HOGDALL EV, CHRISTENSEN L, KJAER SK, BLAAKAER J, KJAERBYE-THYGESEN A et al. CA125 expression pattern, prognosis and correlation with serum CA125 in ovarian tumor patients. From The Danish "MALOVA" Ovarian Cancer Study. Gynecol Oncol 2007; 104: 508-515. http://dx.doi. org/10.1016/j.ygyno.2006.09.028

[21] KANG WD, CHOI HS, KIM SM. Value of serum CA125 levels in patients with high-risk, early stage epithelial ovarian cancer. Gynecol Oncol 2010; 116: 57-60. http://dx.doi.org/10.1016/j. ygyno.2009.09.019

[22] VAN NAGELL JR, JR., PAVLIK EJ. Ovarian cancer screening. Clin Obstet Gynecol 2012; 55: 43-51. http://dx.doi. org/10.1097/GRF.0b013e3182460c0d 
[23] NOSSOV V, AMNEUS M, SU F, LANG J, JANCO JM et al. The early detection of ovarian cancer: from traditional methods to proteomics. Can we really do better than serum CA-125? Am J Obstet Gynecol 2008; 199: 215-223. http:// dx.doi.org/10.1016/j.ajog.2008.04.009

[24] FREDRIKSSON R, GLORIAM DE, HOGLUND PJ, LAGERSTROM MC, SCHIOTH HB. There exist at least 30 human G-protein-coupled receptors with long Ser/Thr-rich Ntermini. Biochem Biophys Res Commun 2003; 301: 725-734. http://dx.doi.org/10.1016/S0006-291X(03)00026-3

[25] HAYFLICK JS. A family of heptahelical receptors with adhesion-like domains: a marriage between two super families. J Recept Signal Transduct Res 2000; 20: 119-131. http://dx.doi. org/10.3109/10799890009150640

[26] HAMANN J, VOGEL B, VAN SCHIJNDEL GM, VAN LIER RA. The seven-span transmembrane receptor CD97 has a cel- lular ligand (CD55, DAF). J Exp Med 1996; 184: 1185-1189. http://dx.doi.org/10.1084/jem.184.3.1185

[27] SUD N, SHARMA R, RAY R, CHATTOPADHYAY TK, RALHAN R. Differential expression of G-protein coupled receptor 56 in human esophageal squamous cell carcinoma. Cancer Lett 2006; 233: 265-270. http://dx.doi.org/10.1016/j.canlet.2005.03.018

[28] ADIB TR, HENDERSON S, PERRETT C, HEWITT D, BOURMPOULIA D et al. Predicting biomarkers for ovarian cancer using gene-expression microarrays. Br J Cancer 2004; 90: 686-692. http://dx.doi.org/10.1038/sj.bjc.6601603

[29] YOSHIHARA K, TAJIMA A, KOMATA D, YAMAMOTO T, KODAMA S et al. Gene expression profiling of advanced-stage serous ovarian cancers distinguishes novel subclasses and implicates ZEB2 in tumor progression and prognosis. Cancer Sci 2009; 100: 1421-1428. http://dx.doi.org/10.1111/j.13497006.2009.01204.x 